\title{
Effect of training on the development of exercise-induced arterial hypoxemia in volleyball players
}

Selcen Korkmaz Eryılmaz ${ }^{1 \mathrm{ABCD}}$, Kerimhan Kaynak ${ }^{2 \mathrm{BE}}$

${ }^{1}$ Cukurova University, Turkey

${ }^{2}$ Erciyes University, Turkey

Authors' Contribution: A -Study design; B -Data collection; C -Statistical analysis; D -Manuscript Preparation; E Funds Collection.

\section{Abstract}

Purpose: $\quad$ The purpose of this study was to examine the effect of volleyball training on the development of exerciseinduced arterial hypoxemia during incremental exercise in male competitive volleyball players.

Material: $\quad$ Eight male amateur volleyball players (age $21 \pm 1.3$ years) participated in a 6-week volleyball training program three times a week in the pre-season preparatory period. All participants were students of the Faculty of Sport Sciences. Before and after the training period, all players performed an incremental treadmill test to determine maximal oxygen uptake $\left(\mathrm{VO}_{2 \max }\right)$, and oxyhemoglobin saturation $\left(\mathrm{SaO}_{2}\right)$ was continuously

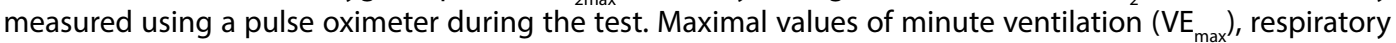
exchange ratio $\left(\mathrm{RER}_{\max }\right)$, ventilatory equivalent for oxygen $\left(\mathrm{VE} / \mathrm{VO}_{2}\right)$ and carbon dioxide $\left(\mathrm{VE} / \mathrm{VCO}_{2}\right)$ were determined. Exercise-induced arterial hypoxemia (EIAH) was defined as a $\mathrm{SaO}_{2}$ decreased by at least $4 \%$ $\left(\Delta \mathrm{SaO}_{2} \leq-4 \%\right)$ from resting level.

Results: $\quad$ All the players exhibited exercise-induced arterial hypoxemia before $\left(\Delta \mathrm{SaO}_{2}=-8.8 \pm 3.3 \%\right)$ and after $\left(\Delta \mathrm{SaO}_{2}=\right.$ $-8.31 .5 \%)$ the training period. $\mathrm{SaO}_{2}$ was significantly decreased from $97.6 \pm 1 \%$ at rest to $88.7 \pm 2.7 \%$ at exhaustion before the training period, and from $97.2 \pm 1.1 \%$ at rest to $88.8 \pm 2.1 \%$ at exhaustion after training period $(p<0.001)$. There was no significant difference in resting and lowest $\mathrm{SaO}_{2}$ values by comparison between the before and after training $(p>0.05)$. There were no significant changes in $V_{2} O_{2 x^{\prime}} V_{m_{m a x}} R^{\prime} R_{m a x}$ $\mathrm{VE} / \mathrm{VO}_{2}$ and $\mathrm{VE} / \mathrm{VCO}_{2}$ after training period $(\mathrm{p}>0.05)$.

Conclusions: The results of this study showed that volleyball players with a history of anaerobic training may exhibit ElAH, but that 6-week volleyball training has no effect on the degree of exercise-induced arterial hypoxemia.

Keywords: desaturation, pulse oximetry, oxyhemoglobin saturation, team sports athletes

\section{Introduction}

Maximal oxygen uptake $\left(\mathrm{VO}_{2 \max }\right)$ is one of the most important factors determining aerobic endurance performance [1]. It has been shown that the respiratory system may be a factor limiting $\mathrm{VO}_{2 \max }$ in healthy athletes [2]. Many athletes have been shown to experience exercise induced arterial hypoxemia in a normoxic environment $[3,4]$. This negative finding accompanied by decreased partial pressure of oxygen in arterial blood may contribute to local muscle fatigue [5]. It has been shown that when the fraction of inspired oxygen increased during exercise, the decrease in oxyhemoglobin saturation $\left(\mathrm{SaO}_{2}\right)$ prevented, the endurance time to exhaustion and $\mathrm{VO}_{2 \max }$ increased [6, 7].

Exercise-induced arterial hypoxemia (EIAH) manifests as decreased partial pressure of oxygen in arterial blood $\left(\mathrm{PaO}_{2}\right)$ or decreased $\mathrm{SaO}_{2}$ below the preexercise level [2]. EIAH is classified as mild (93-95\% $\left.\mathrm{SaO}_{2}\right)$, moderate $\left(88-93 \% \mathrm{SaO}_{2}\right)$, and severe $(<88 \%$ $\mathrm{SaO}_{2}$ ) [2]. The mechanism underlying of EIAH is still not clearly understood. Several potential causes of EIAH including inadequate alveolar hyperventilation, oxygen diffusion limitations, ventilation-perfusion inequality, intra- and extra-pulmonary shunts, low pulmonary capillary blood transit time and interstitial edema or an interaction among these factors have been proposed [2, $8,9,10]$.

(c) Selcen Korkmaz Eryılmaz, Kerimhan Kaynak, 2020 doi:10.15561/20755279.2020.0602
Studies investigating EIAH mostly focused on endurance athletes and reported that EIAH is more common in athletes with high aerobic capacity $[2,3,10$, 11]. The finding of negative correlation between $\mathrm{SaO}_{2}$ and $\mathrm{VO}_{2 \max }$ supported the suggestion that improving aerobic capacity by physical training may be associated with the occurrence of EIAH during strenuous exercise [12]. On the other hand, we and others have recently demonstrated that EIAH can occur in anaerobic trained athletes and nonendurance sportsmen (relatively low $\mathrm{VO}_{2 \max }$ ) $[13,14]$.

A few researchers investigated effects of physical training on EIAH, however, showed different results [12, 14, 15]. Low ventilator chemoresponsiveness may be induced by physical training and it has been suggested that it may contribute to less hyperventilation and therefore EIAH during strenuous exercise in trained subjects $[10,12,14]$. It has been shown that physical traininginduced increases in $\mathrm{VO}_{2 \max }$ were accompanied by more severe EIAH $[12,14]$. On the contrary, Dominelli et al. showed that $\mathrm{VO}_{2 \max }$ increased after physical training, but the degree of EIAH was at the same level as before the training program [15]. To our knowledge, there is no previous study examining the effects of volleyball training on EIAH during incremental exercise.

The purpose of this study was to examine the effect of volleyball training on the development of exerciseinduced arterial hypoxemia during incremental treadmill exercise in male competitive volleyball players. 


\section{Material and Methods}

Participants

Eight male volleyball players (mean $\pm \mathrm{SD}$; age $21 \pm 1.3$ years, height $181.4 \pm 3 \mathrm{~cm}$, body mass $71 \pm 4.7 \mathrm{~kg}$ ) who played in Erciyes University volleyball team volunteered to participate in the present study. All participants were students of the Faculty of Sport Sciences. All players had trained and competed regularly in volleyball for at least 4 years. Measurements were performed following the approval of the Ethics Committee and carried out in accordance with the Declaration of Helsinki. All testing and training procedures were fully explained, and written informed consent was obtained for each participant.

\section{Experimental Design}

The experimental protocol consisted of baseline testing, a 6-week training intervention, and post-testing. Players performed a volleyball training program three times per week for 6 weeks at the beginning of the pre-season preparatory period. All training sessions were conducted at the same time of day on Monday, Wednesday and Friday of each consecutive week. One week before the start of the 6-week training period and two days after its completion all players performed an incremental treadmill test. During the study, the players were not allowed to perform any additional strength and conditioning training that would affect the results of the study.

\section{Data Collection}

Incremental running test was performed on a motorized treadmill (h/p/Cosmos Quasar med, Nussdorf-Traunstein, Germany). Throughout all tests, expired air was measured online using a breath-by-breath cardiopulmonary exercise testing system (Quark PFT Ergo, Cosmed Srl, Rome, Italy). During the incremental testing period, heart rate (HR) was monitored continuously using a wireless HR monitor (S610i, Polar, Finland) and was synchronized to ventilatory signals. Before each test, ambient conditions were measured, and the gas analysers and turbine flowmeter were calibrated with known certified gas concentrations $\left(16 \% \mathrm{O}_{2}, 5 \% \mathrm{CO}_{2}\right.$, and balanced $\left.\mathrm{N}_{2}\right)$ and a $3 \mathrm{~L}$ calibration syringe, respectively, following the manufacturer's instructions.

Breath-by-breath data was smoothed using a five-step average filter and then reduced to $15 \mathrm{~s}$ stationary averages. Maximal oxygen uptake $\left(\mathrm{VO}_{2 \max }\right)$, maximal values of minute ventilation $\left(\mathrm{VE}_{\max }\right)$ and respiratory exchange ratio $\left(\mathrm{RER}_{\max }\right)$, ventilatory equivalent for oxygen $\left(\mathrm{VE} / \mathrm{VO}_{2}\right)$ and carbon dioxide $\left(\mathrm{VE} / \mathrm{VCO}_{2}\right)$ were determined during the incremental treadmill test.

$\mathrm{SaO}_{2}$ was measured continuously and recorded every $15 \mathrm{~s}$ during the incremental treadmill test, using a finger pulse oximeter (Spiropalm 6MWT; COSMED, Rome, Italy). For most accurate readings, the sites were vigorously cleaned with alcohol and gauze pads. EIAH was assumed to have developed when $\mathrm{SaO}_{2}$ decreased by at least $4 \%\left(\Delta \mathrm{SaO}_{2} \leq-4 \%\right)$ from the baseline values [2]. Delta $\mathrm{SaO}_{2}\left(\Delta \mathrm{SaO}_{2}\right)$ was calculated as the difference between rest and maximal exercise values.

\section{Incremental Treadmill Test}

Before test, the players performed a standardized warm-up consisting of a 5 minutes run at their own pace followed by about 3 minutes of stretching. Players started running at $7 \mathrm{~km} / \mathrm{h}$ with speed increments of $1 \mathrm{~km} / \mathrm{h}$ every minute until they could no longer keep pace. All players were given strong verbal encouragement throughout the test to elicit their best performance.

Achievement of $\mathrm{VO}_{2 \max }$ was considered as the attainment of at least two of the following criteria: 1) a plateau in $\mathrm{VO}_{2}$ despite increasing speed, 2) a respiratory exchange ratio $\left(\mathrm{VCO}_{2} / \mathrm{VO}_{2}\right)$ above 1.10 , and 3) a $\mathrm{HR}$ within 10 beats per minute of age-predicted maximum $\mathrm{HR}\left(220\right.$-age). The $\mathrm{VO}_{2 \max }$ was defined as the highest $15 \mathrm{~s} \mathrm{VO}_{2}$ value reached during the incremental test and expressed as a relative value (milliliters per minute per body mass; $\mathrm{ml} / \mathrm{kg} / \mathrm{min}$ ). $\mathrm{VE} / \mathrm{VO}_{2}, \mathrm{VE} / \mathrm{VCO}_{2}, \mathrm{VE}_{\max }$ and $\mathrm{RER}_{\text {max }}$ were expressed as the highest $15 \mathrm{~s}$ average value obtained during the last stage of the incremental exercise test.

\section{Training Program}

A single training session lasted approximately 120 minutes (comprising warm-up, main and cool-down periods). The warm-up period consisted of jogging, different types of running and accelerations, submaximal jumps, mobility exercises, full body stretching and specific volleyball warm-up drills with the ball, and lasted 20-25 minutes. Each training session ended with a 10-15 minutes cool-down consisting of walking and stretching. The main part of the volleyball session consisted of oncourt skills training and the game-based drills including small-sided games and real-game volleyball drills. On-court skills training included serving, passing, and setting in small groups, spiking, blocking and digging drills, as well as skills-based conditioning drills such as lateral movement and blocking, lateral movement and dig drill, moving off of the net and retrieving a ball. Training sessions concluded with high-intensity gamebased drills to work on offensive and defensive strategies and individual tactics. The game-based drills included small-sided games such as 3 vs. 3 and 4 vs. 4, where the volleyball court was divided into two smaller courts, and 6 vs. 6 real-game volleyball drills.

\section{Statistical Analysis:}

Data are reported as mean \pm standard deviation (SD). Statistical significance was accepted at $\mathrm{p}<0.05$. The normality distribution of the data was checked with the Shapiro-Wilk test. Within-group changes before and after the 6-week training period was compared using paired t-test for normally distributed data, and Wilcoxon matched-pair signed-rank test for non-normally distributed data. To allow a better interpretation of the results, effect sizes were also calculated using Cohen's d [16]. Effect sizes were interpreted as negligible $(d \geq 0.2)$, small $(0.2 \leq \mathrm{d} \leq 0.5)$, medium $(0.5 \leq \mathrm{d} \leq 0.8)$ or large $(0.8$ $\geq d$ ). SPSS version 21 was used for all analyses (SPSS Inc., Chicago, IL). 


\section{Results}

Table 1 shows the players' responses to incremental treadmill test. All the players exhibited EIAH (as defined by $\Delta \mathrm{SaO}_{2} \leq-4 \%$ ) before and after the training program (Figure 1). $\mathrm{SaO}_{2}$ was significantly decreased from $97.6 \pm 1$ $\%$ at rest to $88.7 \pm 2.7 \%$ at exhaustion before the training program $(\mathrm{p}<0.001, \mathrm{~d}=5.5)$, and from $97.2 \pm 1.1 \%$ at rest to $88.8 \pm 2.1 \%$ at exhaustion after training program $(\mathrm{p}<0.001, \mathrm{~d}=5.3)$. There was no significant difference in resting $\mathrm{SaO}_{2} \%$ and $\Delta \mathrm{SaO}_{2}$ values by comparison between the before and after training program $(\mathrm{p}>0.05, \mathrm{~d}=0.4)$. The lowest $\mathrm{SaO}_{2} \%$ values occurred at or near $\mathrm{VO}_{2 \max }$ in both exercise tests with no significant difference the before and after training program $(\mathrm{p}>0.05, \mathrm{~d}=0.04)$ (Figure 1).

Figure 2 shows the changes in $\mathrm{SaO}_{2}$ plotted as a percent of the relative work rate (i.e. $\mathrm{VO}_{2 \max } \%$ ). EIAH was begun at $70.4 \pm 21.1 \%$ of maximum work rate (i.e. $\mathrm{VO}_{2 \max } \%$ ) before the training program and at $70.9 \pm 18.1$ $\%$ of maximum work rate after the training program. There were no significant differences in the exercise intensity of began to experience EIAH after training program compared to before $(p>0.05, d=0.03)$. There were no significant changes in $\mathrm{VO}_{2 \max }, \mathrm{VE}_{\max }, \mathrm{RER}_{\max }$, $\mathrm{VE} / \mathrm{VO}_{2}$ and $\mathrm{VE} / \mathrm{VCO}_{2}$ after training program compared to before $(p>0.05)$ (see Table 1).

\section{Discussion}

In the present study, the incremental treadmill test caused EIAH in all volleyball players, and this response was found to be similar after the 6-week volleyball training program. In addition, volleyball training had no statistically effect on $\mathrm{VO}_{2 \max }, \mathrm{VE}_{\max }, \mathrm{RER}_{\max }, \mathrm{VE} / \mathrm{VO}_{2}$ and

Table 1. Results of the incremental treadmill test of the volleyball players before (pre) and after (post) the 6-week training period

\begin{tabular}{|c|c|c|c|c|}
\hline Variables & Pre- training & Post- training & $\mathbf{p}$ & d \\
\hline$\Delta \mathrm{SaO}_{2}(\%)$ & $8.8 \pm 3.3$ & $8.3 \pm 1.5$ & 0.7 & 0.2 \\
\hline $\mathrm{VO}_{2 \max }(\mathrm{ml} / \mathrm{kg} / \mathrm{min})$ & $50.3 \pm 3.1$ & $51.3 \pm 3.3$ & 0.9 & 0.3 \\
\hline $\mathrm{VE}_{\max }(\mathrm{L} / \mathrm{dak})$ & $155.4 \pm 7.7$ & $160.6 \pm 10.8$ & 0.07 & 0.5 \\
\hline $\mathrm{RER}_{\max }$ & $1.16 \pm 0.05$ & $1.2 \pm 0.06$ & 0.2 & 0.7 \\
\hline $\mathrm{VE} / \mathrm{VO}_{2}$ & $41.3 \pm 4.2$ & $42.4 \pm 4.6$ & 0.4 & 0.2 \\
\hline $\mathrm{VE} / \mathrm{VCO}_{2}$ & $37.7 \pm 2.9$ & $36.6 \pm 3.6$ & 0.2 & 0.3 \\
\hline
\end{tabular}

Note: Values are means $\pm \mathrm{SD} ; \mathrm{VO}_{2 \max }=$ maximal oxygen uptake, $\mathrm{RER}_{\max }=$ maximal respiratory exchange ratio, $\mathrm{VE}_{\max }=$ maximal minute ventilation, $\mathrm{VE} / \mathrm{VO}_{2}=$ ventilatory equivalent for $\mathrm{O}_{2}$ at maximal exercise intensity, $\mathrm{VE} / \mathrm{VCO}_{2}=$ ventilatory equivalent for $\mathrm{CO}_{2}$ at maximal exercise intensity, $\Delta \mathrm{SaO}_{2}=$ difference between rest and maximal exercise values of oxyhemoglobin saturation.

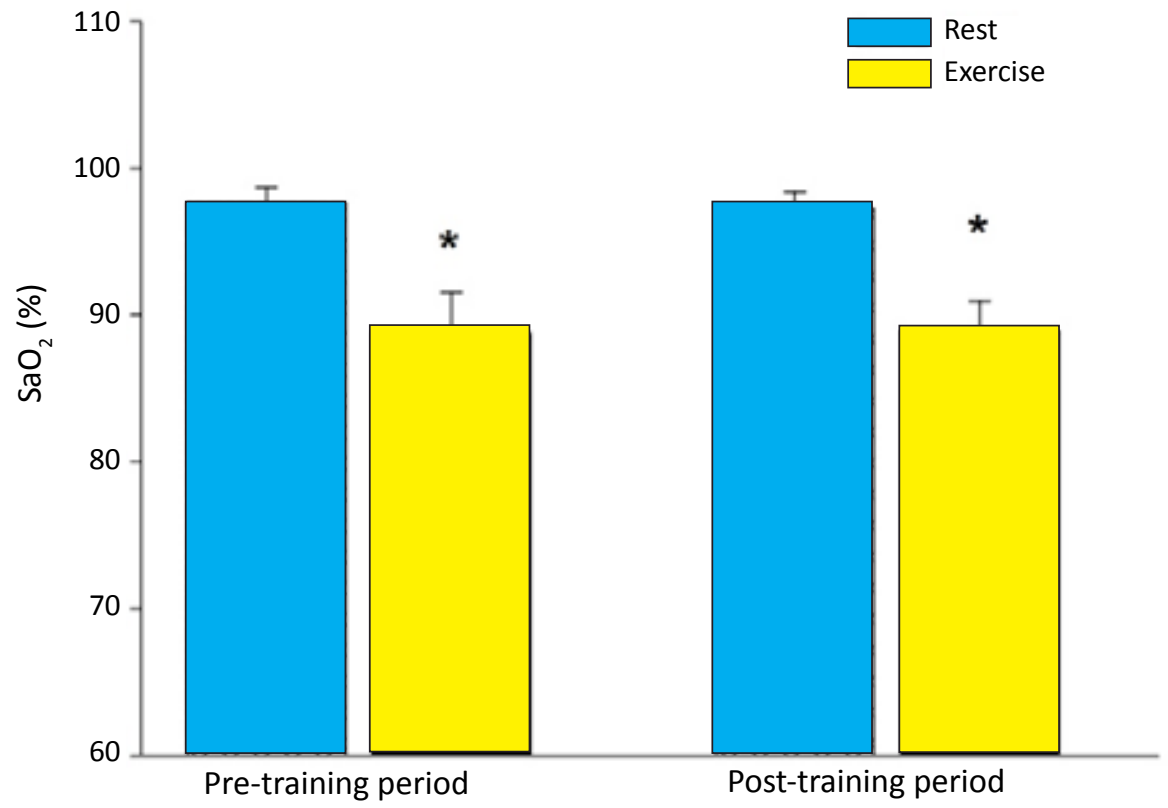

Figure 1.* Significantly different from pre-training (baseline) values. $\mathrm{SaO}_{2}$ values at rest and maximum work rate during incremental treadmill test before (pre) and after (post) the 6-week training period. 


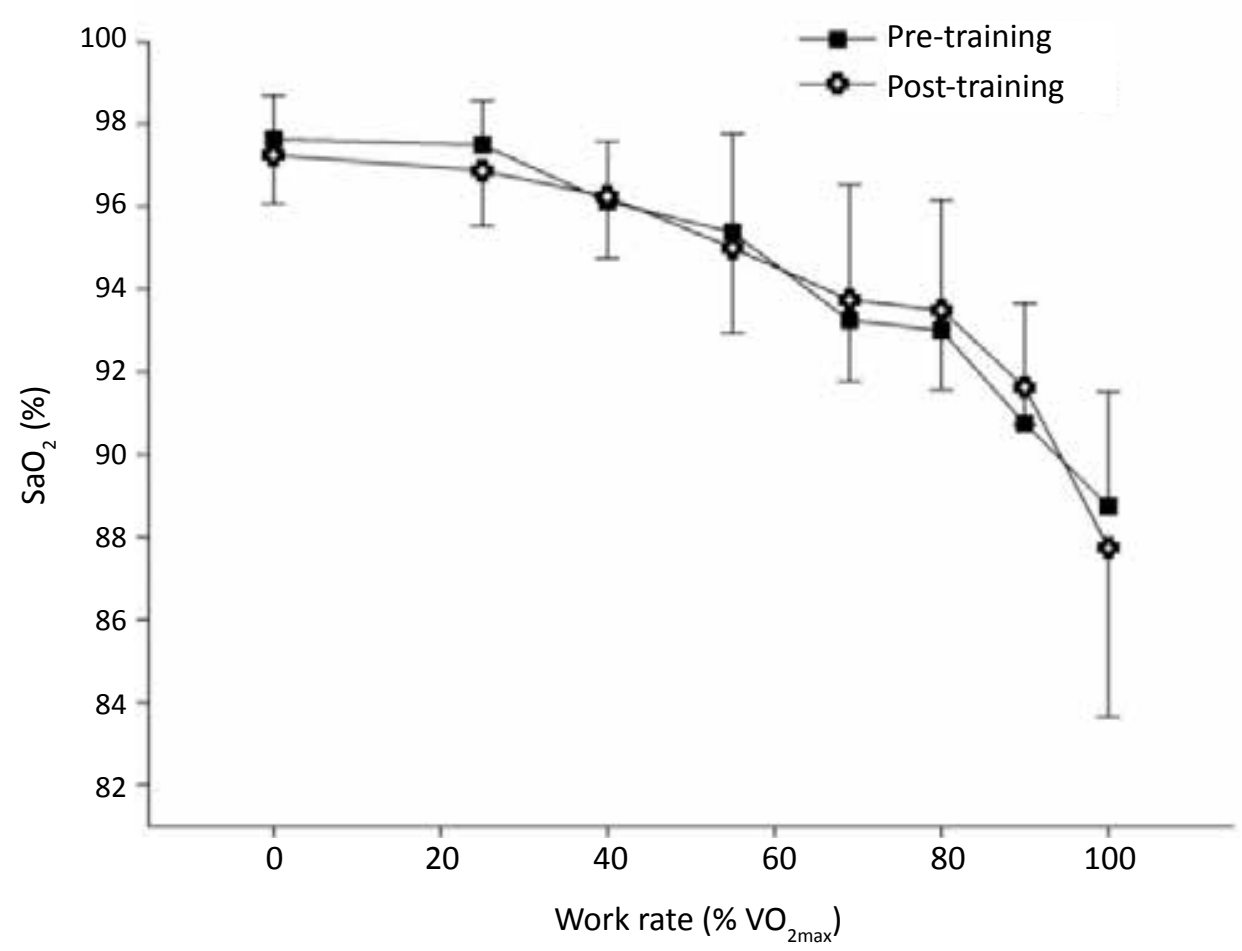

Figure 2. Mean values for the changes in the percent of oxyhemoglobin saturation $\left(\mathrm{SaO}_{2}\right)$ at different percentages of relative work rate during incremental treadmill test before (pre) and after (post) the 6-week training period.

$\mathrm{VE} / \mathrm{VCO}_{2}$. These findings suggest that anaerobic trained athletes may exhibit exercise-induced arterial hypoxemia, but volleyball training has no effect on the degree of exercise-induced arterial hypoxemia.

We found that EIAH occurred in all subjects before and after the training period. On the other hand, previous studies have observed that EIAH did not occur in all trained athletes [4, 17]. In particular, EIAH has been reported to occur mostly in endurance athletes with a $\mathrm{VO}_{2 \max }$ greater than $60 \mathrm{ml} / \mathrm{kg} / \mathrm{min}[3,10,11,17]$. Powers et al. found that $52 \%$ of the highly trained athletes occurred EIAH during incremental cycle exercise test, whereas none of the untrained or moderately trained subjects developed EIAH [17]. A more recent study has shown that EIAH during incremental treadmill exercise occurs in $70 \%$ of well-trained endurance athletes [4]. Differences in measured $\mathrm{SaO}_{2}$ may be explained by differences in exercise modality and types of protocols used $[18,19]$. It has been shown that a greater drop in the $\mathrm{SaO}_{2}$ during treadmill running compared with cycle ergometry exercise in the same subjects [20]. Mucci et al. showed that non-endurance sportsmen developed EIAH after an eight-week supra-maximal interval-training program [14]. In our recent study, we showed that EIAH during incremental treadmill exercise occurred at similar level in both aerobic and anaerobic trained athletes with different aerobic fitness levels [13]. It appears that studies examining EIAH have primarily focused on endurance athletes $[11,17,21]$. The more severe occurrence of EIAH in elite athletes may be due to the trained athletes being able to push their physical capacity to the limit during maximal exercise rather than aerobic capacity level.

Pulse oximetry has been widely used in the literature to determine EIAH and has been recognized as a valid and reliable tool for continuously monitoring $\mathrm{SaO}_{2} \%$ during exercise $[22,23]$. Similar to previous studies using pulse oximetry, in our study, the $\mathrm{SaO}_{2} \%$ values decreased in the range between $85 \%$ and $92 \%$ during incremental exercise $[3,24,25] . \mathrm{SaO}_{2}$ decreased $8.8 \%$ and $8.3 \%$ from rest before and after training period, respectively, similar to previous studies performed during incremental treadmill exercise $[13,26]$. In our study, volleyball players were considered to have developed EIAH when $\mathrm{SaO}_{2}$ fell at least $4 \%\left(\Delta \mathrm{SaO}_{2} \leq-4 \%\right)$ from the baseline values [2]. During the incremental treadmill exercise, we followed the time course of $\mathrm{SaO}_{2}$ from rest state to exhaustion. EIAH developed at the about 70.4 and 70.9 $\%$ of maximum work rate (i.e. $\mathrm{VO}_{2 \max } \%$ ) before and after the training program, respectively, and peaks at or near maximal exercise intensity. There was no difference in the work rate of began to experience EIAH after training program compared to before. Our findings are consistent with studies in the literature showing that EIAH begins to occur at submaximal exercise in some subjects and usually peaks at or near maximal exercise intensity during the incremental exercise $[13,21,27]$. Inadequate hyperventilation and widened alveolar-to-arterial oxygen difference are the most likely mechanisms for EIAH occurs at moderate intensity workloads [2, 9, 21, 27].

There are limited studies in the literature investigating the effect of training on EIAH $[12,13,15]$. Interval training has been shown to increase $\mathrm{VO}_{2 \max }$, while decreasing 
$\mathrm{SaO}_{2}$ more during heavy exercise $[12,14]$. It is suggested that the more severe occurrence of EIAH after training is caused by less alveolar hyperventilation response [12, 14]. In these studies, the decrease in $\mathrm{VE} / \mathrm{VO}_{2}$ after the training period compared to before was interpreted as less hyperventilation response developed with training [12, 14]. Mucci et al. associated the development of EIAH after 8 weeks of interval training with a decrease in $\mathrm{VE} / \mathrm{VO}_{2}$ despite an increase in maximal ventilation during exercise [14]. The decreased hyperventilatory response during strenuous exercise may be related to the lower adaptation of the ventilator system to physical training [12]. It has been suggested that less hyperventilation during strenuous exercise after training period may be related to adaptations in ventilator chemo-responses [12]. Endurance athletes endowed with low ventilator chemo-responses have been reported to breathe less than non-athletes at similar exercise intensities [28]. The low chemoresponsiveness of the respiratory system has been shown to contribute to less hyperventilation and arterial hypoxemia during strenuous exercise [10, 29]. Granger et al. suggested that chemoreceptor sensitivity to carbon dioxide may play a role in the development of EIAH in aerobically trained athletes, partially explaining the variability in EIAH occurrence and severity [10]. $\mathrm{VO}_{2 \max }$ did not change after 6 weeks of volleyball training in our study. In addition, it may be suggested that less hyperventilation response did not develop with volleyball training, as there were no significant changes in $\mathrm{VE} / \mathrm{VO}_{2}$ and $\mathrm{VE} / \mathrm{VCO}_{2}$. As a matter of fact, no difference was found in the degree of EIAH in volleyball players after the training program compared to before. The ability of the neuromuscular system to produce power during intense exercises such as various sprints, jumps and high-intensity court movement is the most important factor determining athletic performance in volleyball [30]. Volleyball training may not include physiological adaptations to improve the aerobic capacity of athletes.

On the other hand, exercise-induced arterial hypoxemia has been suggested to not necessarily worsen with aerobic training [15]. There are some researchers showing that aerobic training did not increase the severity of EIAH [15]. Dominelli et al. showed that female runners' $\mathrm{VO}_{2 \max }$ increased after five months of endurance training, but the degree of EIAH remained similar during the maximal exercise test [15]. Some researchers reported that arterial hypoxemia during strenuous exercise was accompanied by less hyperventilation response and lower alveolar oxygen partial pressure $[21,31]$. On the contrary, others concluded that the increase in alveolo-arterial oxygen pressure difference $\left(\mathrm{A}-\mathrm{aDO}_{2}\right)$ plays a major role in the occurrence of arterial hypoxemia during strenuous exercise and ventilation contributes less [32]. It has been reported that the increase in $\mathrm{A}-\mathrm{aDO}_{2}$ during strenuous exercise is mainly due to oxygen diffusion limitation caused by the shortening of the pulmonary capillary blood transit time when cardiac output reaches its maximum in trained athletes $[21,11]$. One of the possible causes of the increase in $\mathrm{A}-\mathrm{aDO}_{2}$ is the increase in ventilationperfusion mismatch as a result of the greater increase in minute ventilation volume compared to perfusion during exercise [9]. In addition, the development of interstitial pulmonary edema due to a high cardiac output during exercise contributes to the enlargement of $\mathrm{A}-\mathrm{aDO}_{2}$ by decreasing $\mathrm{PaO}_{2}$ [2]. However, there are very few longitudinal studies examining the specific effect of aerobic or anaerobic training on EIAH. Our data represent a rather novel finding that could be of considerable importance for showing occurrence of EIAH in volleyball players, but that volleyball training has no effect on the severity of EIAH.

\section{Conclusions}

The results of this study showed that volleyball players with a history of anaerobic training may exhibit exercise-induced arterial hypoxemia, but that 6-week volleyball training has no effect on the degree of exerciseinduced arterial hypoxemia. Further research is needed to investigate the effects of training on exercise-induced arterial hypoxemia in in different team sport branches.

\section{Conflict of interest}

Authors declare no conflict of interest. 
. LanferdiniFJ,SilvaES, MachadoE,FischerG,Peyré-Tartaruga LA. Physiological Predictors of Maximal Incremental Running Performance. Frontiers in Physiology, 2020; 11: 979. https://doi.org/10.3389/fphys.2020.00979

2. DempseyJA, WagnerPD.Exerciseinducedarterialhypoxemia. Journal of applied physiology, 1999; 87:1997-2006. https://doi.org/10.1152/jappl.1999.87.6.1997

3. Powers SK, Lawler J, Dempsey JA, Dodd S, Landry G. Effects of incomplete pulmonary gas exchange on $\mathrm{VO}_{2}$ Journal of Applied Physiology. 1989; 66(6):2491-5. https://doi.org/10.1152/jappl.1989.66.6.2491

4. Constantini K, Tanner DA, Gavin TP, Harms CA, Stager JM, Chapman RF. Prevalence of exercise-induced arterial hypoxemia in distance runners at sea level. Medicine and Science in Sports and Exercise, 2017; 49:948-954. https://doi.org/10.1249/MSS.0000000000001193

5. Dominelli PB, Molgat-Seon Y, Griesdale DEG, Peters CM, Blouin JS, Sekhon M., et al. Exercise-induced quadriceps muscle fatigue in men and women: effects of arterial oxygen content and respiratory muscle work. The Journal of Physiology, 2017; 595(15): 5227-5244. https://doi.org/10.1113/JP274068

6. Harms CA, McClaran SR, Nickele GA, Pegelow DF, Nelson WB, Dempsey JA. Effect of exercise-induced arterial $\mathrm{O}_{2}$ desaturation on $\mathrm{VO}_{2 \max }$ in women. Medicine and Science in Sports and Exercise. 2000; 32(6):1101-8. https://doi.org/10.1097/00005768-200006000-00010

7. Ohya T, Yamanaka R, Ohnuma H, Hagiwara M, Suzuki Y. Hyperoxia extends time to exhaustion during high-intensity intermittent exercise: a randomized, crossover study in male cyclists. Sports Medicine-Open, 2016; 2(1): 34. https://doi.org/10.1186/s40798-016-0059-7

8. Hopkins SR, McKenzie DC, Schoene RB, Glenny RW, Robertson HT. Pulmonary gas exchange during exercise in athletes. I. Ventilation-perfusion mismatch and diffusion limitation. Journal of Applied Physiology, 1994; 77(2), 912-917. https://doi.org/10.1152/jappl.1994.77.2.912

9. Dominelli PB, Sheel AW. Exercise-induced arterial hypoxemia; some answers, more questions. Applied Physiology, Nutrition, and Metabolism, 2019; 44(6):571-579. https://doi.org/10.1139/apnm-2018-0468

10.Granger EA, Cooper TK, Hopkins SR, McKenzie DC, Dominelli P. Peripheral chemoresponsiveness during exercise in male athletes with exercise-induced arterial hypoxaemia. Experimental Physiology. 2020;44(6);571- 579. https://doi.org/10.1113/EP088639

11. Williams JH, Powers SK, Stuart MK. Hemoglobin desaturation in highly trained athletes during heavy exercise. Medicine and Science in Sports and Exercise. 1986; 18:168-73. https://doi.org/10.1249/00005768-198604000-00004

12.Miyachi M, Katayama K. Effects of maximal interval training on arterial oxygen desaturation and ventilation during heavy exercise. The Japanese Journal of Physiology, 1999; 49(5), 401-407. https://doi.org/10.2170/jjphysiol.49.401

13.Korkmaz Eryılmaz S, Polat M. Exercise-induced arterial hypoxemia in aerobic and anaerobic trained athletes during incremental exercise. Physical Education of Students, 2018; 22(2): 99-103. https://doi.org/10.15561/20755279.2018.0207

14.Mucci P, Blondel N, Fabre C, Nourry C, Berthoin S. Evidence of exercise-induced $\mathrm{O}_{2}$ arterial desaturation in non-elite sportsmen and sportswomen following high-intensity interval-training.

International Journal of Sports Medicine, 2004; 25(01):6-13. https://doi.org/10.1055/s-2003-45225

15.Dominelli PB, Foster GE, Dominelli GS, Henderson WR, Koehle MS, McKenzie DC, et al. Exerciseinduced arterial hypoxemia is unaffected by intense physical training: a case report. Applied Physiology, Nutrition, and Metabolism, 2014; 39(2):266-269. https://doi.org/10.1139/apnm-2013-0341

16.Thalheimer W, Cook S. How to calculate effect sizes from published research articles: A simplified methodology. Available at: http://work learning.com/effect_sizes.htm. Accessed on January 11, 2016.

17.Powers SK, Dodd S, Lawler J, Landry G, Kirtley $\mathrm{M}$, McKnight $\mathrm{T}$, et al. Incidence of exercise induced hypoxemia in elite endurance athletes at sea level. European Journal of Applied Physiology, 1988; 58:298-302. https://doi.org/10.1007/BF00417266

18.Galy O, Le Gallais D, Hue O, Boussana A, Prefaut C. Is Exercise-induced arterial hypoxemia in triathletes dependent on exercise modality?. International Journal of Sports Medicine, 2005; 26(9):719-726. https://doi.org/10.1055/s-2005-837446

19.Rasmussen J, Hanel B, Diamant B, Secher NH. Muscle mass effect on arterial desaturation after maximal exercise. Medicine and Science in Sports and Exercise, 1991; 23:1349-1352. https://doi.org/10.1249/00005768-199112000-00005

20.Tanner DA, Duke JW, Stager JM. Ventilatory patterns differ between maximal running and cycling. Respiratory Physiology \& Neurobiology, 2014; 191, 9-16. https://doi.org/10.1016/j.resp.2013.10.011

21.Dempsey JA, Hanson PG, Henderson KS. Exerciseinduced arterial hypoxaemia in healthy human subjects at sea level. Journal of Physiology. 1984; 355:161-175. https://doi.org/10.1113/jphysiol.1984.sp015412

22.Martin D, Powers S, Cicale M, Collop N, Huang D, Criswell D. Validity of pulse oximetry during exercise in elite endurance athletes. Journal of Applied Physiology, 1992; 72(2):455-458. https://doi.org/10.1152/jappl.1992.72.2.455

23.Mollard P, Bourdillon N, Letournel M, Herman H, Gibert S, Pichon A, et al. Validity of arterialized earlobe blood gases at rest and exercise in normoxia and hypoxia. Respiratory Physiology Neurobiology, 2010; 172(3):179-183. https://doi.org/10.1016/j.resp.2010.05.017

24.Brown DD, Knowlton RG, Sanjabi PB, Szurgot BT. Re-examination of the incidence of exerciseinduced hypoxaemia in highly trained subjects. British Journal Sports Medicine, 1993; 27(3):167-70. https://doi.org/10.1136/bjsm.27.3.167

25.Gaston AF, Durand F, Roca E, Doucende G, Hapkova I, Subirats E. Exercise-induced hypoxaemia developed at sea-level influences responses to exercise at moderate altitude. PLoS One, 2016; 11(9): e0161819. https://doi.org/10.1371/journal.pone.0161819

26.Alis R, Sanchis-Gomar F, Ferioli D, La Torre A, Blesa JR, Romagnoli M. Exercise Effects on Erythrocyte Deformability in Exercise-induced Arterial Hypoxemia. International Journal of Sports Medicine, 2015; 36(4):286-91. https://doi.org/10.1055/s-0034-1394395

27.Rice AJ, Scroop GC, Gore CJ, Thornton AT, Chapman MJ, Greville HW, et al. Exercise-induced hypoxaemia in highly trained cyclists at $40 \%$ peak oxygen uptake. European Journal of Applied Physiology, 1999; 79(4):353-359. https://doi.org/10.1007/s004210050520

28.Martin B, Sparks K, Zw1llich C, We1l J. Low exercise 
ventilation in endurance athletes. Medicine and Science in Sports, 1979; 11(2):181-185.

29. Miyachi M, Tabata I. Relationship between arterial oxygen desaturation and ventilation during maximal exercise. Journal of Applied Physiology, 1992; 73(6):2588-2591. https://doi.org/10.1152/jappl.1992.73.6.2588

30.Hakkinen K. Changes in physical fitness profile in female volleyball players during the competitive season. Journal of Sport Medicine and Physical Fitness, 1993; 33(3):223-232.

31.Powers SK, Dodd S, Woodyard J, Beadle RE,
Church G. Haemoglobin saturation during incremental arm and leg exercise. British Journal Sports Medicine, 1984; 18(3):212-216. https://doi.org/10.1136/bjsm.18.3.212

32.Powers SK, Martin D, Cicale M, Collop N, Huang D, Criswell D. Exercise-induced hypoxemia in athletes: role of inadequate hyperventilation. European Journal of Applied Physiology and Occupational Physiology, 1992; 65(1):37-42. https://doi.org/10.1007/BF01466272

\section{Information about the authors:}

Selcen Korkmaz Eryılmaz; (Corresponding Author); http://orcid.org/0000-0002-3680-3580; selcen_korkmaz@yahoo.com; Department of Coaching Education, Faculty of Sport Science, Cukurova University; 01330 Balcalı, Sarıçam. Adana. Turkey.

Kerimhan Kaynak; http://orcid.org/0000-0002-5608-2661; kerimhankaynak07@hotmail.com; Department of Coaching Education, Faculty of Sport Science, Erciyes University; Kayseri, Turkey.

Cite this article as:

Korkmaz Eryılmaz S, Kaynak K. Effect of training on the development of exercise-induced arterial hypoxemia in volleyball players. Physical Education of Students, 2020;24(6):312-318.

https://doi.org/10.15561/20755279.2020.0602

This is an Open Access article distributed under the terms of the Creative Commons Attribution License, which permits unrestricted use, distribution, and reproduction in any medium, provided the original work is properly cited http://creativecommons.org/licenses/by/4.0/deed.en

Received: 09.10.2020

Accepted: 12.11.2020; Published: 30.12.2020 